\title{
Evidence-Based Practice Questionnaire: A Confirmatory Factor Analysis in a Social Work Sample
}

\author{
Karen Rice \\ Jeongha Hwang \\ Tina Abrefa-Gyan \\ Kathleen Powell
}

\begin{abstract}
This study examined the psychometric properties of the Evidence-Based Practice Questionnaire (EBPQ). The 24-item EBPQ was developed to measure health professionals' attitudes toward, knowledge of, and use of evidence-based practice (EBP). $A$ confirmatory factor analysis was performed on the EBPQ given to a random sample of National Association of Social Work members $(N=167)$. The coefficient alpha of the EBPQ was .93. The study supported a 23-item 3-factor model with acceptable model fit indices $\left(\chi^{2}=469.04 ; R M S E A=.081 ; S R M R=.068 ; C F I=.900\right)$. This study suggests a slightly modified EBPQ may be a useful tool to assess social workers' attitudes toward, knowledge of, and use of EBP.
\end{abstract}

Keywords: Evidence-based practice, confirmatory factor analysis, EBPQ, social workers

\section{INTRODUCTION}

Evidence-based practice (EBP) is defined as a "process that blends current best evidence, community values and preferences, and agency, societal, and political considerations in order to establish programs and policies that are effective and contextualized” (Regehr, Stern, \& Shlonsky, 2007, p. 410). In most developed countries, use of EBP is the goal of public services (Nutley, Walter, \& Davies, 2009), and in the past two decades, there has been a more conscientious attempt to use EBP in various social work settings including child welfare, employment, health, juvenile justice, mental health, and substance abuse (Fixsen, Blase, Naoom, \& Wallace, 2009).

The degree to which EBP is used varies among practitioners and across practice settings (McNeece \& Thyer, 2004). Bellamy, Bledsoe, and Traube (2006) note that many federal agencies including the National Institute of Mental Health (NIMH) and the Substance Abuse and Mental Health Services Administration (SAMHSA) have emphasized the use of evidence-based interventions and are now linking their grants to translational research.

\footnotetext{
Karen Rice, MSW, is an Instructor in the Department of Social Work at Millersville University in Millersville, PA, and a Ph.D. student at the University of Maryland, Baltimore. Jeongha Hwang and Tina Abrefa-Gyan are Ph.D. students at the University of Maryland, Baltimore. Kathleen Powell, MSW, is an Associate Professor in the Department of Social Work at Frostburg State University in Frostburg, MD as well as a Ph.D. student at the University of Maryland, Baltimore. This research was supported by funds from the University of Maryland, Baltimore School of Social Work as part of a doctoral practicum project. The authors wish to thank Drs. Llewellyn J. Cornelius and Donna Harrington for their technical assistance and professional mentoring. In addition, the authors wish to thank the following student colleagues for their assistance with the project: Margaret Beall, Darnell Morris-Compton, Saltanat Dushalieva, Andrea Jones, Marlene Materese, Deborah Vangeison Svoboda, Kimberly Searce VanVulpen, Michelle Tuten, and Crystal Williams. Finally, special thanks are given to Dominic and Penelope Upton for allowing the use of their measure.
} 
Social workers, however, do not generally incorporate research evidence into daily practice despite being encouraged, or sometimes required to do so (Bledsoe et al., 2007; Mullen, Bledsoe, \& Bellamy, 2008; National Association of Social Workers, 1999; Rosen, 2003). In fact, some practitioners have actively resisted the use of EBP (Gibbs, 2003; Nelson, Steele, \& Mize, 2006). In an attempt to understand the resistance to the use of EBP, research has been done on barriers to implementing EBP (Bellamy et al., 2006). The findings reveal that negative attitudes toward EBP (Aarons, 2004; Addis \& Krasnow, 2000; Rosen, 2003) and lack of knowledge and skills for using EBP (Addis \& Krasnow, 2000; Rosen, 2003) are the two most frequently cited barriers impeding practitioners' use of EBP.

To ensure that attitudes toward and knowledge of EBP are measured consistently across the diverse population of social workers, it is essential to have reliable and valid measures (Harrington, 2009). A review of the literature identified scales measuring attitudes toward, knowledge of, and/or use of EBP developed for use in the health or mental health professions, but not explicitly for social work. To determine whether the original structure of a measure works well in a new population such as social work, a confirmatory factor analysis (CFA) can be performed (Harrington, 2009), which is the purpose of this research study. As Upton and Upton (2006) noted, the psychometric properties of the Evidence-Based Practice Questionnaire (EBPQ), the instrument used in this study, need to be evaluated for further refinement. Thus, the purpose of this study is to assess the reliability and validity of the EBPQ with a sample of National Association of Social Work members.

\section{LITERATURE REVIEW}

A review of the literature was conducted to identify potential standardized scales that measure social service providers' knowledge of, attitudes towards, and use of EBP. A search using keywords: "evidence-based practice" or "evidence-based interventions" and "measures" or "instruments" was conducted using Academic Search Premier, Social Science Index, PsycINFO, PubMed, and HAPI databases. The search produced three potential EBP scales that have been used in the health professions, particularly in nursing. These scales included the 15-item Evidence-Based Practice Attitude Scale (EBPAS) developed by Aarons (2004); the 24-item Evidence-Based Practice Questionnaire (EBPQ) developed by Upton and Upton (2006); and the joint 16-item EBP Beliefs Scale and 18-item EBP Implementation Scale developed by Melnyk, Fineout-Overholt, and Mays (2008).

\section{Evidence-Based Practice Beliefs and Implementation Scales}

The 16-item EBP Beliefs and 18-item EBP Implementation scales (Melnyk et al., 2008) were designed to be used jointly to measure nurses' attitudes toward and use of evidence-based practice. Both scales are unidimensional constructs. The EBP Beliefs scale has response categories ranging from $1=$ strongly disagree and $5=$ strongly agree with higher scores indicating higher value of EBP and belief in implementing it in practice. The EBP Implementation scale's response categories range from $0=0$ times to

$4=>8$ times with higher scores indicating increased frequency in implementing EBP 
within the past eight weeks. High internal consistency reliability was attained for each scale (alpha $=.90$ for EBP Beliefs and alpha $=.96$ for EBP Implementation), and criterion validity was also supported. These scales were recently developed and the developers continue to test their reliability and validity.

\section{Evidence-Based Practice Attitude Scale}

The 15-item EBPAS was designed to measure mental health service providers' attitudes about adopting new or different therapies or interventions with a sample of 322 public sector clinical service workers from 51 programs (Aarons, 2004). Approximately one-third of the sample was comprised of social workers. Response categories on the EBPAS range from $0=$ not at all to $4=$ to a very great extent. Using two separate factor analytic procedures, exploratory factor analysis and confirmatory factor analysis, a fourfactor solution was found in the study as follows: (a) intuitive Appeal of EBP (alpha = .80), (b) likelihood of adopting EBP given Requirements to do so (alpha = .90), (c) Openness to new practices (alpha $=.78$ ), and $(\mathrm{d})$ perceived Divergence of usual practice with research-based/academically developed intervention (alpha $=.59$ ). Subsequent studies have tested the validity of the EBPAS (Aarons, 2006; Aarons, McDonald, Sheehan, \& Walrath-Greene, 2007). Aarons' (2006) study of 303 public-sector mental health clinicians and case managers, including 99 social workers, from 49 programs yielded an overall alpha of .77 for the EBPAS with subscale alphas ranging from .59 to .90. The Aarons et al. (2007) study of 221 mental health service providers, including 99 social workers, resulted in an overall alpha of .79 for the EBPAS with subscale alphas ranging from .66 to .93.

\section{Evidence-Based Practice Questionnaire}

Finally, Upton and Lewis (1998) laid the groundwork for the EBPQ in an effort to record healthcare professionals' attitudes toward and knowledge of the concepts of evidence-based practice. Upton (1999) subsequently refined the measure with a sample of 370 nurses, midwives, and health visitors. Upton and Upton (2006) then examined the factor structure of the 24-item EBPQ and found a three-factor structure in a pilot study of 500 randomly selected nurses in the United Kingdom. Following a principal components analysis, three distinct subscales, attitudes toward, knowledge of, and use of EBP emerged. Cronbach's alpha for each subscale exceeded .70. The EBPQ is not based on theory, but rather on prior quantitative and qualitative research related to barriers to EBP. The scale was found to have good construct and discriminant validity in a random sample of 751 nurses. Construct validity was supported by positive correlations ranging from 0.3 to $0.4(p<.001)$ between the measure and an independent measure of awareness of EBP. Discriminant validity was assessed by comparing those who were knowledgeable about a local EBP initiative with those who were not; those who were knowledgeable of the initiative had a better attitude $[t(332)=2.5, p<.001]$, more frequent use of EBP [ $t$ (360) $=3.2, p<.02]$, and better knowledge of EBP $[t(360)=5.2, p<.001]$ than individuals without knowledge of the local EBP initiative. Additionally, the subscales were reported to have adequate internal consistency including an alpha of .79 for attitudes toward EBP, an alpha of .91 for knowledge of EBP, an alpha of .85 for use of EBP, and an overall alpha of .87 . 
Ultimately, the EBPQ scale was selected as it incorporated all three of the constructs that the study sought to examine: attitudes toward, knowledge of, and use of EBP, unlike the EBPAS, which measures attitudes only, and the EBP Beliefs and EBP Implementation Scales, which measure attitudes and use of EBP, but not knowledge of EBP. The incorporation of all three major constructs in one scale contributed to the goal of reducing the level of burden placed on potential respondents.

\section{Purpose of the Study}

EBP has made its way into the social work profession with an increasing expectation that social work practitioners will utilize evidence to guide their practice. However, no scale measuring social workers' attitudes toward, knowledge of, and use of EBP exists. The EBPQ was developed to measure these constructs within the nursing profession, but had not been used with a sample of social workers. The purpose of this study is to determine whether the EBPQ can be used as a reliable and valid tool with a sample of social workers, which helps validate this tool across professional disciplines.

\section{METHOD}

\section{Participants}

A random sample of 1000 current members of the National Association of Social Workers (NASW) was obtained. This sample was subsequently randomly divided into two groups of 500 each; individuals in one group received a mail survey and the other group received a URL link to an internet survey. Two modes of delivery were used to assess the viability of each mode in reaching social work practitioners. Fourteen invitations were returned undeliverable (11 from mail group and 3 from internet group), and seven participants ( 1 from the mail group and 6 from the internet group) refused to participate. Further, of the mail surveys returned, two cases were deleted due to failure to complete the survey. Forty individuals completed the internet survey (8\% response rate). This response rate is close to the average $10-11 \%$ typically yielded from an internetbased survey (Dillman, Smyth, \& Melani-Christian, 2009). Combined with the 140 mail survey respondents (28\% response rate), the total sample yielded 180 participants. Table 1 presents the demographics of this study's participants. On average, participants were female $(n=135)$, White $(n=148)$, and held a Masters degree in social work $(n=145)$, with a mean age of 49 years old $(S D=14.21)$ and $18.2(S D=13.7)$ years of practice experience. The current sample characteristics are consistent with the $2008 \mathrm{NASW}$ Membership Workforce Study compiled by Whitaker and Arrington (2008), which indicated that the majority of NASW members are female, White, MSW educated, older (median age of 50), and experienced (with most having more than 16 years of practice experience). 
Table 1: $\quad$ Select Sample Demographics $(\mathrm{N}=167)$

\begin{tabular}{|c|c|c|}
\hline Sample Characteristics & $\mathbf{N}$ & $\%$ \\
\hline \multicolumn{3}{|l|}{ Gender } \\
\hline Female & 135 & 80.8 \\
\hline Male & 30 & 18.0 \\
\hline Missing data & 2 & 1.2 \\
\hline \multicolumn{3}{|l|}{ Race } \\
\hline White/Caucasian & 148 & 88.6 \\
\hline Black/African American & 9 & 5.4 \\
\hline Hispanic/Latino & 5 & 3.0 \\
\hline Asian & 4 & 2.4 \\
\hline American Indian/Alaska Native & 1 & 0.6 \\
\hline \multicolumn{3}{|l|}{ Highest Degree } \\
\hline Bachelors degree & 5 & 3.0 \\
\hline Masters degree & 145 & 86.8 \\
\hline Doctoral degree & 15 & 9.0 \\
\hline Missing data & 2 & 1.2 \\
\hline \multicolumn{3}{|l|}{ Employment Status } \\
\hline Unemployed & 9 & 5.4 \\
\hline Employed full-time & 114 & 68.3 \\
\hline Employed part-time & 28 & 16.8 \\
\hline Retired & 17 & 10.2 \\
\hline \multicolumn{3}{|l|}{ Geographical Area } \\
\hline Rural & 26 & 15.6 \\
\hline Urban & 86 & 51.5 \\
\hline Suburban & 55 & 32.9 \\
\hline \multicolumn{3}{|l|}{ Area of Practice } \\
\hline Addictions & 10 & 6.0 \\
\hline Adolescents & 7 & 4.2 \\
\hline Aging & 14 & 8.4 \\
\hline Child Welfare/Family & 19 & 11.4 \\
\hline Community Development & 2 & 1.2 \\
\hline Criminal Justice & 1 & 0.6 \\
\hline Developmental/Rehabilitative Disabilities & 6 & 3.6 \\
\hline Health & 14 & 8.4 \\
\hline Mental Health & 81 & 48.5 \\
\hline School Social Work & 9 & 5.4 \\
\hline Other & 10 & 6.0 \\
\hline \multicolumn{3}{|l|}{ Direct Clinical Social Work } \\
\hline Direct & 132 & 79.0 \\
\hline No direct & 33 & 19.8 \\
\hline Missing data & 2 & 1.2 \\
\hline
\end{tabular}




\begin{tabular}{lrr}
\hline & & \\
\hline & (Table 1. Cont.) & SD \\
Years of experience & 18.2 & 13.7 \\
Age & 49.2 & 14.2 \\
\hline
\end{tabular}

\section{Procedure}

Upon obtaining permission from the measure's authors and exempt status from the university's Institutional Review Board, the EBPQ (Upton \& Upton, 2006) was administered to a group of members of NASW as part of a larger cross-sectional study. A modified approach of Dillman and colleagues' (2009) mailing recommendations was employed in order to prevent over-burdening respondents, as well as to reduce the extra costs and time associated with Dillman and colleagues' process. The mail group respondents were sent a cover letter and survey; whereas, the internet group was sent a letter with the URL address to access the online survey through Survey Monkey (2009). Both groups were sent a reminder postcard 3-weeks after the first mailing. The survey asked respondents to rate their attitudes toward, knowledge of, and use of evidence-based practice by completing the EBPQ (Upton \& Upton, 2006). Participants were not compensated for responding to the survey.

\section{Measure}

The survey included the 24-item EBPQ (Upton \& Upton, 2006), which consists of three subscales: attitudes toward, knowledge of, and use of EBP. Each item is scored on a 7-point Likert-type scale with responses ranging from 1 (Poor/Never) to 7 (Best/Frequently) and higher scores indicating a more positive attitudes toward, knowledge of, or use of EBP. The attitudes toward EBP subscale is comprised of 4 items, the knowledge of EBP subscale consists of 14 items, and the use of EBP subscale is made up of 6 items. However, there is some variation in the structure of the subscale responses. For example, the attitude toward EBP subscale requires participants to indicate their attitude somewhere between opposite pairs of statements (e.g., "Evidence based practice is a waste of time" to "Evidence based practice is fundamental to professional practice"); whereas, the other two subscales do not utilize this paired statement approach.

\section{Data Analysis}

SPSS 17.0 for Windows (2009) was used to analyze demographics and compute Cronbach's alpha. Internal consistency reliability of the full EBPQ and three subscales was examined using Cronbach's alpha. To identify items that may not fit well within each subscale, alphas if item deleted were also examined. All statistical analyses were interpreted with an alpha level of .05.

A confirmatory factor analysis was performed on the EBPQ using Mplus (Muthén \& Muthén, 2005). Multiple fit indices are available for evaluating the goodness-of-fit of the model; therefore, the following fit indices were used: chi-square, the comparative fit index (CFI), root mean square error of approximation (RMSEA) with 90\% confidence 
interval, and standardized root mean square residual (SRMR). Values $>.90$ were indicative of good model fit using the CFI; RMSEA close to .06 or less, and SRMR close to .08 or less also indicate good fit (Hu \& Bentler, 1999). Consistent with Upton and Upton (2006), factor loadings $>.4$ were used as the criterion for including items on a subscale.

In the current study, the initial model (with 24-item, 3-factor) did not fit well. To analyze the missing pattern, a new variable was created by computing the percent of missingness using NMISS function in SPSS. As a result, 13 cases were removed due to having $25 \%$ or more missingness. Modifications based on modification indices (MI) or examination of residuals were considered. To examine the MI, SPSS missing values analysis (MVA) using the expectation maximizing (EM) algorithm was used to impute missing data for this sample as recommended by Schafer and Graham (2002). As a result, the full 167 sample size was retained for further CFAs.

Additionally, the normality assumption using skewness and kurtosis indices was checked for each item using the following criteria: skewness index absolute value $>3$, kurtosis index absolute value $>10$ (Kline, 2005). The assumption was met for this sample (see Table 2).

\section{RESULTS}

\section{Internal Consistency Reliability}

Cronbach's alpha was .93 for the knowledge of EBP subscale and was .90 for the use of EBP subscale, both well above the recommended .70 cutoff for good internal consistency reliability (de Vaus, 2002). The overall scale yielded an alpha of .93; however, the attitudes toward EBP subscale yielded a Cronbach's alpha of .64. Because the attitudes toward EBP subscale fell below the recommended alpha of .70, alphas if item-deleted were examined. Removal of Item 1 ("My workload is too great for me to keep up-to-date with all the new evidence.”) would result in an alpha of .69, suggesting this item does not fit well with the other three items on this subscale.

\section{Confirmatory Factor Analysis}

Using the subscales identified by Upton and Upton (2006), a 3-factor CFA model was examined. Because of the change in alpha for the attitudes toward EBP subscale that resulted from dropping Item 1 , the 3 -factor model was run with and without Item 1 . The chi-square difference test (Kline, 2005) was used to assess whether changes to the model (deletion of Item 1) resulted in an improved model fit. The original 24-item model resulted in $\chi^{2}(252, N=167)=844.361$; whereas, the 23-item model yielded a $\chi^{2}(230, N$ $=167)=789.402$. The change in $\chi^{2}=55.959(22, N=167)$ between the models indicates the model improved significantly $(p<.001)$ without Item 1 . Therefore, all subsequent CFAs were run without this item. 
Table 2: $\quad$ EBPQ Item Statistics Including Assumption Checking ( $\quad$ = 167)

\begin{tabular}{|c|c|c|c|c|}
\hline Item & $\mathbf{M}$ & SD & Skewness & Kurtosis \\
\hline \multicolumn{5}{|l|}{ Attitudes Toward EBP } \\
\hline $\begin{array}{l}\text { My workload is too great for me to keep up to date } \\
\text { with all the new evidence }\end{array}$ & 4.44 & 1.63 & -0.16 & -0.89 \\
\hline I resent having my clinical practice questioned & 5.53 & 1.53 & -1.11 & 0.71 \\
\hline Evidence-based practice is a waste of time & 5.69 & 1.47 & -1.34 & 1.71 \\
\hline $\begin{array}{l}\text { I stick to tried and trusted methods rather than } \\
\text { changing to anything new }\end{array}$ & 5.54 & 1.26 & -0.75 & 0.52 \\
\hline \multicolumn{5}{|l|}{ Knowledge of EBP } \\
\hline Research skills & 4.33 & 1.50 & -0.25 & -0.54 \\
\hline Information technology skills & 4.71 & 1.46 & -0.32 & -0.72 \\
\hline Monitoring and reviewing of practice skills & 4.73 & 1.06 & -0.18 & -0.50 \\
\hline $\begin{array}{l}\text { Converting your information needs into a research } \\
\text { question }\end{array}$ & 3.89 & 1.53 & -0.04 & -0.55 \\
\hline Awareness of major information types and sources & 4.73 & 1.24 & -0.07 & -0.58 \\
\hline Ability to identify gaps in your professional practice & 5.10 & 1.09 & -0.25 & -0.28 \\
\hline Knowledge of how to retrieve evidence & 4.68 & 1.32 & -0.22 & -0.45 \\
\hline $\begin{array}{l}\text { Ability to analyze critically evidence against set } \\
\text { standards }\end{array}$ & 4.51 & 1.31 & -0.28 & -0.42 \\
\hline $\begin{array}{l}\text { Ability to determine how valid (close to the truth) } \\
\text { the material is }\end{array}$ & 4.59 & 1.24 & -0.39 & -0.19 \\
\hline $\begin{array}{l}\text { Ability to determine how useful (clinically } \\
\text { applicable) the material is }\end{array}$ & 4.98 & 1.11 & -0.50 & 0.21 \\
\hline Ability to apply information to individual cases & 5.37 & 1.06 & -0.79 & 1.36 \\
\hline Sharing of ideas and information with colleagues & 5.46 & 1.20 & -0.70 & 0.57 \\
\hline Dissemination of new ideas about care to colleagues & 5.14 & 1.27 & -0.66 & 0.33 \\
\hline Ability to review your own practice & 5.28 & 1.04 & -0.76 & 2.30 \\
\hline \multicolumn{5}{|l|}{ Use of EBP } \\
\hline $\begin{array}{l}\text { How often have you formulated a clearly } \\
\text { answerable question as the beginning of the } \\
\text { process towards filling this gap? }\end{array}$ & 4.19 & 1.68 & -0.20 & -0.75 \\
\hline $\begin{array}{l}\text { How often have you tracked down the relevant } \\
\text { evidence once you have formulated the question? }\end{array}$ & 4.41 & 1.64 & -0.28 & -0.59 \\
\hline $\begin{array}{l}\text { How often have you critically appraised, against set } \\
\text { criteria, any literature you have discovered? }\end{array}$ & 4.07 & 1.75 & -0.22 & -0.81 \\
\hline $\begin{array}{l}\text { How often have you integrated the evidence you } \\
\text { have found with your expertise? }\end{array}$ & 4.57 & 1.67 & -0.54 & -0.51 \\
\hline $\begin{array}{l}\text { How often have you evaluated the outcomes of your } \\
\text { practice? }\end{array}$ & 4.41 & 1.63 & -0.19 & -0.72 \\
\hline $\begin{array}{l}\text { How often have you shared this information with } \\
\text { colleagues? }\end{array}$ & 4.29 & 1.76 & -0.19 & -0.89 \\
\hline
\end{tabular}


Given that the 23-item, 3-factor model did not fit adequately, an examination of the modification indices suggested that the model fit could be improved by allowing several of the item errors to correlate. These modifications were made one at a time until the fit indices marginally met the cutoff criteria for acceptable levels. Error correlations occurred between Items 17 and 16, 8 and 5, 13 and 12, 20 and 19, 14 and 13, 18 and 16, and 18 and 17. All 23 items had significant loadings $>.4$, using the criterion set by Upton and Upton (2006) in their original study. The final model yielded a model $\chi^{2}(223, N=$ $167)=469.041, p<.0005$; RMSEA $=0.081$ (90\% CI 0.071-0.092); SRMR $=0.068$; CFI $=0.900$. The chi-square difference between the second and the final model is $320.361(\mathrm{~d} f$ $=7)$ indicating a significant improvement $(p<.001)$ in model fit. A graphic illustration of this final model is displayed in Figure 1 , and Table 3 provides a summary of CFA goodness-of-fit indices by analysis.

\section{DISCUSSION}

The Evidence-Based Practice Questionnaire (Upton \& Upton, 2006) is a 24-item, self-report survey measuring attitudes toward, knowledge of, and use of evidence-based practice. This study supported a 23-item, three subscale structure of the EBPQ with seven error covariances. Different from the original EBPQ work done by Upton and Upton (2006), this study did not support retaining Item 1 on the attitudes toward EBP subscale, resulting in the final 23-item EBPQ. Item 1 asks respondents to examine the impact their workload has on their ability to use evidence within their practice; whereas, the remaining three items on the attitudes toward EBP assess perceptions of the usefulness of evidence on one's practice. This item may not have fit well due to the sample differences between this study and Upton and Upton's (2006) study that surveyed nurses. The original survey was developed using a group of nurses; whereas, this study's sample consists of a range of social work practitioners (e.g., clinical practitioners, case managers, and administrators). Many social workers, regardless of area of practice, are able to relate to workload demands and the impact these demands have on their daily activities. For example, many workload studies within child welfare have confirmed the impact high workloads have on a caseworker's ability to effectively engage and spend quality time with children, families, and caregivers (Child Welfare League of America, 2007). Not all social workers, however, are engaged in direct practice, and in examining the three remaining items on the attitudes toward EBP subscale, the emphasis is on clinical practice, which could explain the discrepancy in how this subscale fit within this sample of social workers.

The format of the attitudes toward EBP subscale may also have impacted the findings. Unlike the knowledge and use of EBP subscales, the attitudes toward EBP subscale uses paired statements to anchor the 7-point Likert scale. For example, Item 1 was anchored with the following statements: 1 = "My workload is too great for me to keep up to date with all the new evidence" and $7=$ "New evidence is so important that I make the time in my work schedule." In fact, these items may be distinct and able to stand on their own, rather than representing opposite pairs. Additionally, Dillman et al. (2009) caution against using such a format due to the possibility of confusing respondents, which may increase response error. 
Figure 1: $\quad$ 3-Factor Confirmatory Factor Analysis of 23-item EBPQ with 7 Error Covariances and Standardized Estimates

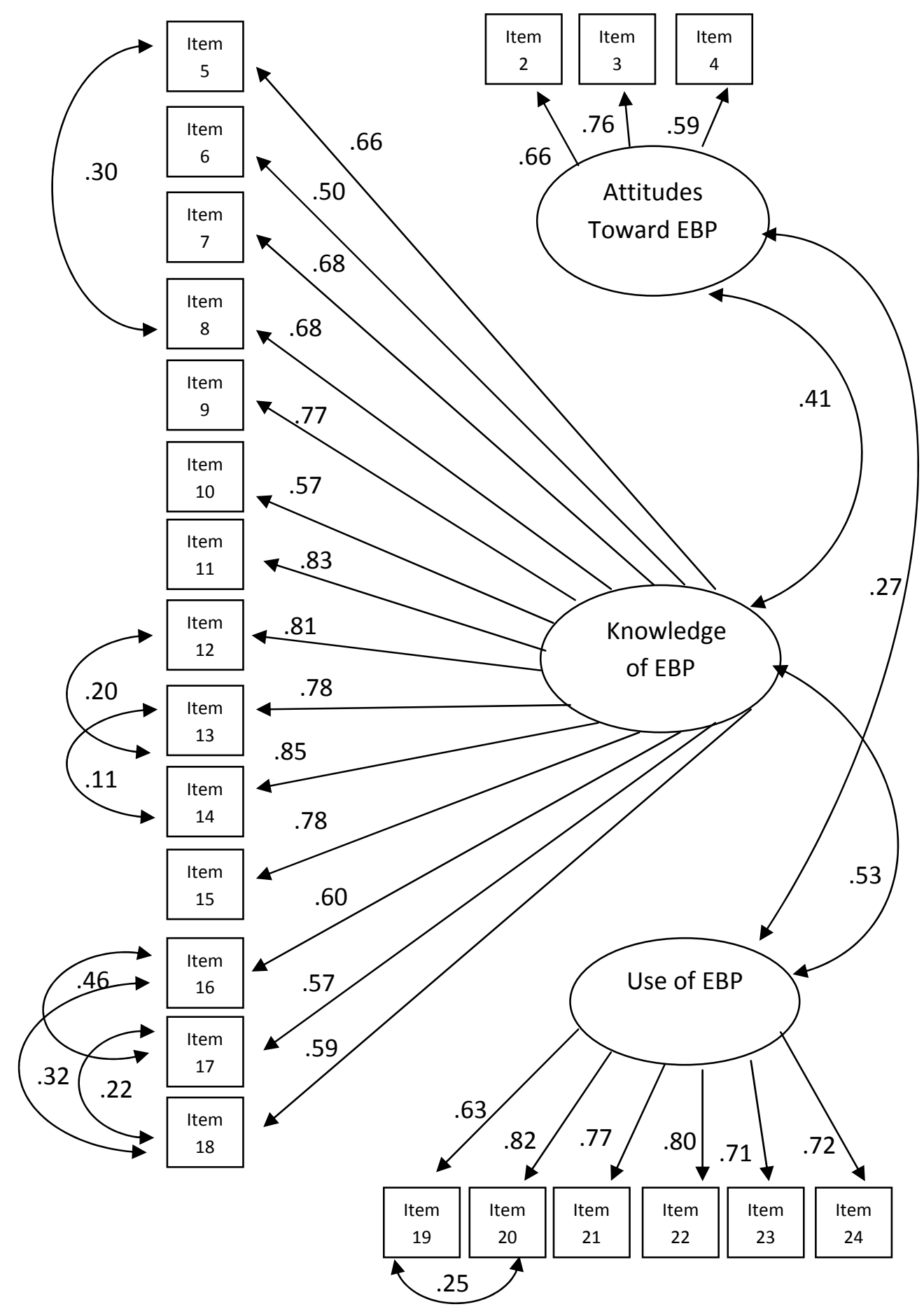


Table 3: $\quad$ Goodness-of-Fit Indices ( $\quad$ = 167)

\begin{tabular}{|c|c|c|c|c|c|}
\hline Model & $\chi^{2}(d f)$ & $\begin{array}{l}\text { RMSEA } \\
(90 \% \text { CI })\end{array}$ & SRMR & CFI & $\begin{array}{l}\text { Number } \\
\text { of Items }\end{array}$ \\
\hline $\begin{array}{l}\text { 3-Factor Model (with } \\
\text { Item 1) }\end{array}$ & $\begin{array}{l}844.361 \\
(252)\end{array}$ & $\begin{array}{c}0.119 \\
(0.110-0.128)\end{array}$ & 0.091 & 0.765 & 24 \\
\hline $\begin{array}{l}\text { 3-Factor Model } \\
\text { (without Item 1) }\end{array}$ & $\begin{array}{c}789.402 * \\
(230)\end{array}$ & $\begin{array}{c}0.121 \\
(0.112-0.130)\end{array}$ & 0.088 & 0.773 & 23 \\
\hline $\begin{array}{l}\text { 3-Factor Model with } \\
7 \text { Error Covariances } \\
\text { (without Item 1) }\end{array}$ & $\begin{array}{l}469.041^{*} \\
(223)\end{array}$ & $\begin{array}{c}0.081 \\
(0.071-0.092)\end{array}$ & 0.068 & 0.900 & 23 \\
\hline
\end{tabular}

* Change in chi-square indicated significant improvement of model fit at $p<.001$.

The final 23-item 3-factor EBPQ required seven error covariances, as suggested from the modification indices, before obtaining an adequate goodness-of-fit model. Bloom, Fischer, and Orme (2009) define EBP as a process that involves developing a question, finding the evidence, analyzing the evidence, combining the evidence with your understanding of the client situation, applying the evidence to practice, and monitoring and evaluating your results. In examining the error covariances, Item 8 explores respondents' knowledge in converting information into a research question, and Item 5 explores respondents' knowledge in finding the evidence. It is not surprising, therefore, that as one item varies, the other will too. Further, Items 13 and 12 examine respondents' ability to analyze the evidence. Finally, Items 14 and 13 covary as Item 13 explores the ability to determine how valid the evidence is and Item 14 explores respondents' ability to determine the clinical applicability of the evidence.

As for the error covariances between Items 17 and 16, 18 and 16, and 18 and 17, they can best be explained as addressing social workers' ethical responsibility to evaluate their practice and disseminate that knowledge. The NASW Code of Ethics (1999) indicates that social workers have an obligation to monitor and evaluate their practice, as well as contribute to the development of knowledge. Adding the covariances between these items' errors, therefore, seems reasonable.

The last error covariance was between Items 20 and 19, both on the use of EBP subscale. Item 19 asks respondents their frequency in developing answerable questions and Item 20 explores their frequency in tracking down relevant evidence to answer the questions. These items support Bloom and colleagues' (2009) definition of evidencebased practice being a process that requires social workers to develop the research question and find the evidence to answer it. For that reason, adding the covariance between these items' errors makes sense. 


\section{Strengths and Limitations}

The study's sample was demographically similar to the NASW membership and sufficient to detect a medium effect size (Kline, 2005). It is possible, however, that those who did not respond to the survey may have differed in significant ways from those who did respond. Furthermore, some of the model fit indices may have been influenced by the small sample size. For example, the noncentral chi-square distribution used in the RMSEA fit index is not well approximated in samples under 200 because it may lead to skewed values of model fit (Curran, Bollen, Poxton, Kirby, \& Chen, 2002). In addition, the study's small sample is below Kline's (2005) recommendation of a minimum sample of 200. Marsh and Hau (1999) suggest using indicators with good psychometric properties where factor loadings are greater than .60 to compensate for a limited sample size. In this study, factors loaded at .50 or greater, thus approaching Marsh and Haus' suggested minimum, and exceeding Kline's .40 recommendation. The current study made several model modifications (e.g., error covariances and dropping Item 1) to the original measure while ensuring that the specified model retained at least three indicators for each latent variable per Kline's (2005) recommendation. Still, the small sample does mean that caution should be exercised in interpreting the study's findings, although this study's response rate was not wholly inconsistent with expected response rates for other "coldcontact” surveys that have used these mediums (Aday \& Cornelius, 2006).

Although the final EBPQ model was slightly modified (deletion of Item 1 and seven error covariances) in order to fit this sample of social workers, this may be reflective of the inherent differences between the two professions, nursing and social work. The professional model of EBP has its origins in medicine and is described as the use of best evidence in guiding the decision-making process regarding the care of individual patients (Sackett, Rosenberg, Gray, Haynes, \& Richardson, 1996). Adopting EBP has not been an easy task for professionals in any discipline (Glasgow, Lichtenstein, \& Marcus, 2003; Mullen, Shlonsky, Bledsoe, \& Bellamy, 2005). In particular, social work as a profession has lagged behind in embracing the use of evidence to guide practice with clients (Mullen et al., 2005) and continues to hold onto what may be considered humanistic motivations (Thyer, 2008). The error covariances that emerged within this sample of social workers seem understandable as they are potentially more reflective of the social work profession's process in utilizing evidence to inform practice. In summary, the greatest contribution of this study is that it helps validate the only known tool that measures attitudes toward, knowledge of, and use of EBP.

\section{Implications for Research and Practice}

The final 23-item three-factor (see Figure 1) model produced acceptable fit indices; therefore, this analysis contributes to the ongoing refinement of the EBPQ as a measure to evaluate social workers' attitudes toward, knowledge of, and use of EBP. Due to the paucity of scales examining EBP use, many primarily exploring attitudes toward EBP (e.g., Aaron, 2004; Melnyk et al., 2008), the EBPQ offers a good alternative. Given the challenges and potential influences on the social work profession of EBP use, it is essential that the profession's practice evidence base be identified or clearly articulated. In line with this, the EBPQ may be a reliable measure that should continue to be used for 
improving credibility among social workers and closing the gap between research and practice in the field. Further research using the 23-item three-factor model is warranted, however. In particular, the 23-item three-factor model is recommended because use of this revised tool will further the development and confirmation of the three-factor EBPQ structure. Specifically, larger sample sizes and samples that are diverse in terms of age, race, ethnicity, and practice settings are necessary to examine whether there are differences in attitudes toward, knowledge of, and use of EBP among various social work populations.

There is a need for evaluative research on the equivalence of measurement models across distinct groups (e.g., culturally different groups and different practice disciplines such as social work and nursing). Multiple-group CFA will be a useful analysis to evaluate the generalizability of a construct across population subgroups (Brown, 2006). Ultimately, there is the need for a qualitative study that examines how well this measure assesses all relevant facets of the construct of EBP in social work. The recently adopted Council on Social Work Education Educational Policy Accreditation Standards (2008) encourages social work scholars and educators to devote more attention to the teaching of EBP in the classroom and to helping social work students and practitioners learn how to utilize the process of evidence-based practice as well as the use of evidence-based interventions. Specifically, the revised EBPQ could be used as a tool to evaluate social work students' performance in the field with regards to their attitudes toward and knowledge and use of EBP.

\section{CONCLUSION}

Evidence-based practice is an attempt to bridge the gap between research and practice (Hagell \& Spencer, 2004); therefore, finding a survey that measures social workers' attitudes toward, knowledge of, and use of EBP is essential in order to increase the use of evidence in social work practice. In this study, the EBPQ demonstrated adequate psychometric properties in a sample of social work practitioners. Although this instrument was not primarily developed for testing among social work professionals, findings from this study contribute to the sparse psychometric evidence on the instrument and its promise for use with social workers.

\section{References}

Aarons, G. A. (2004). Mental health provider attitudes toward adoption of evidence based practice: The evidence-based practice attitude scale (EBPAS). Mental Health Services Research, 6, 61-74. doi: 10.1023/B:MHSR.0000024351.12294.65

Aarons, G. A. (2006). Transformational and transactional leadership: Association with attitudes toward evidence-based practice in mental health services. Psychiatric Services, 57, 1162-1169. doi: 10.1176/appi.ps.57.8.1162

Aarons, G. A., McDonald, E. J., Sheehan, A. K., \& Walrath-Greene, C. M. (2007). Confirmatory factor analysis of the evidence-based practice attitude scale (EBPAS) in a geographically diverse sample of community mental health providers. 
Administrative Policy in Mental Health and Mental Health Services Research, 34, 465-469. doi: 10.1007/s10488-007-0127-x

Aday, L. A., \& Cornelius, L. J. (2006). Designing and conducting health surveys ( ${ }^{\text {rd }}$ ed.). San Francisco, CA: John Wiley and Sons, Inc.

Addis, M. E., \& Krasnow, A. D. (2000). A national survey of practicing psychologists' attitudes toward psychotherapy treatment manuals. Journal of Consulting and Clinical Psychology, 68, 331-339. doi: 10.1037//0022-006x.68.2

Bellamy, J. L., Bledsoe, S. E., \& Traube, D. E. (2006). The current state of evidencebased practice in social work: A review of the literature and qualitative analysis of expert interviews. Journal of Evidence-Based Social Work, 3, 23-48. doi: 10.1300/J367v03n01_02

Bledsoe, S. E., Weissman, M. M., Mullen, E. J., Ponniah, K., Gameroff, M., Verdeli, H., ...Wickramaratne, P. (2007). Empirically supported psychotherapy in social work training programs: Does the definition of evidence matter? Research on Social Work Practice, 17, 449-455. doi: 10.1177/1049731506299014

Bloom, M., Fischer, J., \& Orme, J. G. (2009). Evaluating practice: Guidelines for the accountable professional ( $6^{\text {th }}$ ed.). Boston, MA: Pearson.

Brown, T. A. (2006). Confirmatory factor analysis for applied research. New York, NY: The Guilford Press.

Child Welfare League of America (2007). Child welfare standards of excellence. Arlington, Virginia: Author. Retrieved from http://www.cwla.org

Council on Social Work Education (2008). Education policy and accreditation standards. Alexandria, VA: Author. Retrieved from http://www.cswe.org

Curran, P. J., Bollen, K. A., Poxton, P., Kirby, J. B., \& Chen, F. (2002). The noncentral chi-square distribution in misspecified structural equation model: Finite sample results from a Monte Carlo simulation. Multivariate Behavioral Research, 37, 1-36. doi: 10.1207/S15327906MBR3701_01

de Vaus, D. (2002). Analyzing social science data: 50 key problems in data analysis. Los Angeles, CA: Sage.

Dillman, D. A., Smyth, J. D., \& Melani-Christian, L. (2009). Mail and internet surveys: The tailored design method ( $3^{\text {rd }}$ ed.). Hoboken, NJ: John Wiley and Sons, Inc.

Fixsen, D. L., Blase, K. A., Naoom, S. F., \& Wallace, F. (2009). Core implementation components. Research on Social Work Practice, 19, 531-540. doi: $10.1177 / 1049731509335549$

Gibbs, L. E. (2003). Evidence-based practice for the helping professions: A practical guide to integrated multimedia. Pacific Grove, CA: Brooks/Cole.

Glasgow, R. E., Lichtenstein, E., \& Marcus, A. C. (2003). Why don't we see more translation of health promotion research to practice? Rethinking the efficacy-to- 
effectiveness transition. American Journal of Public Health, 93(8), 1261-1267. Retrieved from http://ajph.aphapublications.org/contents-by-date.0.shtml

Hagell, A., \& Spencer, L. (2004). An evaluation of an innovative audiotape method for keeping social care staff up to date with the latest research findings. Child and Family Social Work, 9, 187-196. doi: 10.1111/j.1365-2206.2004.00313.x

Harrington, D. (2009). Confirmatory factor analysis. New York, NY: Oxford University Press.

Hu, L., \& Bentler, P. M. (1999). Cuttoff criteria for fit indexes in covariance structure analysis: Conventional criteria versus new alternative. Structural Equation Modeling, 6, 1-55. doi: 10.1080/10705519909540118

Kline, R. B. (2005). Principles and practice of structural equation modeling ( $2^{\text {nd }}$ ed.). New York, NY: Guilford.

Marsh, H. W., \& Hau, K. T. (1999). Confirmatory factor analysis: Strategies for small sample sizes. In R. H. Hoyle (Ed.), Statistical strategies for small sample research (pp. 251-284). Thousand Oaks, CA: Sage.

McNeece, C. A., \& Thyer, B. A. (2004). Evidence-based practice and social work. Journal of Evidence-Based Social Work, 1, 7-25. doi: 10.1300/J394v01n01_02

Melnyk, B. M., Fineout-Overholt, E., \& Mays, M. Z. (2008). The evidence-based practice beliefs and implementation scales: Psychometric properties of two new instruments. Worldviews on Evidence-Based Nursing, 4, 208-216. doi: 10.1111/j.1741-6787.2008.00126.x

Mullen, E. J., Bledsoe, S. E., \& Bellamy, J. L. (2008). Implementing evidence-based social work practice. Research on Social Work Practice, 18, 325-338. doi: 10.1177/1049731506297827

Mullen, E. J., Shlonsky, A., Bledsoe, S. E., \& Bellamy, J. L. (2005). From concept to implementation: Challenges facing evidence-based social work. Evidence \& Policy: A Journal of Research, Debate and Practice, 1, 61-84. doi: 10.1332/1744264052703159

Muthén, L. K., \& Muthén, B. O. (2005). Mplus Version 3.13. Los Angeles, CA: Author.

National Association of Social Workers. (1999). Code of ethics. Washington DC: Author.

Nelson, T. D., Steele, R. G., \& Mize, J. A. (2006). Practitioner attitudes toward evidencebased practice: Themes and challenges. Administration and Policy in Mental Health, 33, 398-409. doi: 10.1007/s1048800600444

Nutley, S., Walter, I., \& Davies, H. T. O. (2009). Promoting evidence-based practice: Models and mechanisms from cross-sector review. Research on Social Work Practice, 19, 552-559. doi: 10.1177/1049731509335496

Patterson, M., West, M., Shackleton, V., Lawthom, R., Maitlis, S., Robinson, D., ...Wallace, A. (2004). Development and validation of an organization climate 
measure. Aston Academy for Research in Management, Aston University, Birmingham, UK, B4 7ET.

Regehr, C., Stern, S., \& Shlonsky, A. (2007). Operationalizing evidence-based practice: The development of an institute for evidence-based social work. Research on Social Work Practice, 17, 409-416. doi: 10.1177/1049731506293561

Rosen, A. (2003). Evidence-based social work practice: Challenges and promise. Social Work Research, 27, 197-208. Retrieved from http://www.ingentaconnect.com/content/nasw/ swr/2003/00000027/00000004/art00002

Sackett, D. L., Rosenberg, W. M. C., Gray, J. A. M., Haynes, R. B., \& Richardson, W. S. (1996). Evidence-based medicine: What it is and what it isn't. British Medical Journal, 312, 71-72. Retrieved from http://www.ncbi.nlm.nih.gov/pubmed/8555924

Schafer, J. L., \& Graham, J. W. (2002). Missing data: Our view of the state of the art. Psychological Methods, 7, 147-177. doi: 10.1037//1082-989X.7.2.147

SPSS, Inc. (2009). SPSS 17.0 for Windows. Chicago, IL: Author.

Survey Monkey. (2009). Software for professional surveys [Computer software]. Retrieved from http://www.surveymonkey.com

Thyer, B. A. (2008). The quest for evidence-based practice?: We are all positivists! Research on Social Work Practice, 18, 339-345. doi: 10.1177/1049731507313998

Upton, D. (1999). Attitudes towards, and knowledge of, clinical effectiveness in nurses, midwives, practice nurses and health visitors. Journal of Advanced Nursing, 29(4), 885-893. Retrieved from http://www3.interscience.wiley.com/journal/ 118486802/home?CRETRY $=1 \&$ SRETRY $=0$

Upton, D., \& Lewis, B. K. (1998). Clinical effectiveness and EBP: Design of a questionnaire. British Journal of Therapy and Rehabilitation, 5(12), 647-650. Retrieved from http://www.ijtr.co.uk

Upton, D., \& Upton, P. (2006). Development of an evidence-based practice questionnaire for nurses. Journal of Advanced Nursing, 54, 454-458. doi: 10.1111/j.13652648.2006.03739.x

Whitaker, T., \& Arrington, P. (2008). Social workers at work: NASW membership workforce study. Washington, D. C.: National Association of Social Workers. Retrieved from http://workforce.socialworkers.org/clearinghouse/default.asp

\section{Author's note:}

Address correspondence to: Karen Rice, Department of Social Work, Millersville University, P.O. Box 1002, 1 South George St., Millersville, PA 17551. Email: karen.rice@millersville.edu 